\title{
CIUDADANÍA Y DEFINICIONES
}

Antonio-Enrique Pérez Luño

Universidad de Sevilla

\section{Planteamiento}

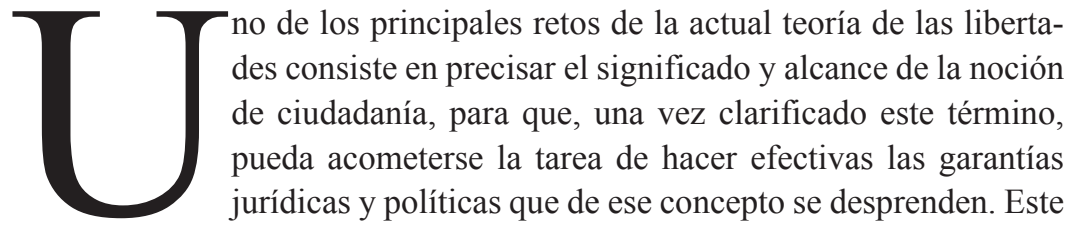
capítulo tiene por objeto avanzar algunas reflexiones tendentes a discernir esa problemática. En aras de ese propósito, tratará de precisar, dentro de los usos lingüísticos de la expresión "ciudadanía", aquél que se estima más pertinente para la teoría de los derechos fundamentales; se hará eco de los motivos más invocados por quienes han planteado la crisis de la ciudadanía en las sociedades democráticas; y, por último, tratará de justificar la persistencia del concepto de ciudadanía como marco de referencia para la participación democrática en los procesos jurídicos y políticos de los Estados de derecho.

\section{Para un mapa lingüístico de la ciudadanía: sus acepciones lexicales}

No deja de ser paradójico que la noción de ciudadanía, uno de los ejes en torno al cual se gestó la concepción moderna de las libertades en el siglo XVIII, constituya hoy, cuando se inicia el siglo XXI, una de las categorías más asidua y ubicuamente invocadas en la esfera de los derechos fundamentales. En el lenguaje jurídico y político del presente, se alude de forma constante y, en muchas ocasiones con significación diversa, al término "ciudadanía". Conviene no dejar esta noción a la intemperie, sin abrigo de aclaraciones, expuesta a contraer las significaciones más arbitrarias y confusas.

Es tarea insoslayable de la teoría de los derechos fundamentales del presente urbanizar esa jungla de sentidos, distintos y hasta opuestos, de la "expresión" ciudadanía, para evitar que la misma quede ofuscada y borrosa. Para ese propósito clarificador resulta oportuno partir de una relación de los principales significados de uso del término "ciudadanía”. Se trata de esbozar una especie de mapa lingüístico que reseñe algunos de los contextos básicos 
en los que dicha expresión es asiduamente invocada. Para ello, convendrá recurrir a lo que, en el seno de las teorías analítico-lingüística, se denominan definiciones lexicales. Este tipo de definiciones describen usos lingüísticos y significados de los términos, a partir de cómo se comprueban en la praxis lingüística efectiva de las personas individuales y los grupos (cfr. Pérez Luño,1997, 30 ss id.; 2002, 49ss.).

En función de esas premisas lexicales se pueden consignar, entre otros, los siguientes usos lingüísticos del término "ciudadanía":

\subsection{Descriptivo / prescriptivo}

En determinadas ocasiones, el término "ciudadanía"se utiliza en sentido descriptivo. Ese es su significado más frecuente en la teoría jurídica iuspublicista. Para los estudiosos del Derecho constitucional y del Derecho administrativo, la ciudadanía se traduce en un conjunto de normas que regulan el status jurídico-político de los ciudadanos. Se trata, por tanto, de una categoría o institución que dimana del derecho positivo estatal y cuya definición se elabora a partir del análisis empírico y de la exégesis de ese sector normativo del ordenamiento jurídico.

Como ejemplo notorio de esta acepción del significado de la ciudadanía, cabe aludir al Discurso pronunciado por Rudolf Smend en la Universidad de Berlín en 1933 sobre Ciudadano y burgués en el Derecho político alemán. En esa disertación Smend expone, con lucidez y rigor impecables, el sentido y alcance de la condición de ciudadano que se desprende de las normas de la Constitución de Weimar, en una etapa en que comienzan a percibirse las amenazas de lo que poco después se traduciría en la ominosa experiencia política del nazismo (Smend, 1985).

Por contra, en la filosofía moral y política abundan las concepciones prescriptivas de la ciudadanía. En ellas, esta noción reviste el significado deontológico y contrafáctico de un modelo ideal de status que debiera reconocerse a los miembros de la sociedad política. Este es el significado que puede atribuirse, por ejemplo, a la propuesta de una "ciudadanía diferenciada” formulada por el profesor Will Kymlicka (1996).

\subsection{Teórico / pragmático}

El uso teórico de la noción de ciudadanía se ha plasmado en un amplio panorama bibliográfico del presente, que se concreta en aportaciones doctrinales multidisciplinarias: filosóficas, jurídicas, sociológicas, políticas...

Han entrañado un sentido muy diverso, de manifiesta intencionalidad pragmática, las apelaciones a la ciudadanía realizadas por quienes la han invocado o invocan como bandera en la lucha reivindicativa por la consecución de determinadas libertades o situaciones jurídico-políticas. Así, el mo- 
vimiento en favor de los derechos civiles en la sociedad norteamericana de la segunda mitad del pasado siglo, o la lucha contra el apartheid en la Unión Sudafricana, así como las acciones de determinados colectivos cívicos y ONGS que reivindican la ampliación de la ciudadanía europea a cuantos refugiados, inmigrantes y extranjeros habitan en los diversos países integrados en la Unión Europea. Ese tipo de actitudes constituyen ejemplos notorios de la dimensión pragmática que puede asumir el lenguaje de la ciudadanía.

\subsection{Natural / político}

En las teorías contemporáneas de orientación comunitarista, prevalece una acepción natural de la ciudadanía. Se la concibe como un factor innato y necesario que determina la inserción del individuo en el grupo étnico y/o cultural al que pertenece.

En un trabajo reciente, titulado: El concepto de "ciudadanía" en una sociedad que cambia, Michael Walzer expresa con nitidez los presupuestos básicos de la postura comunitarista en relación con la ciudadanía. Según se desprende de su planteamiento, el liberalismo ha forjado una noción formal y adjetiva de ciudadanía, como algo que es exterior al sujeto. Mientras que para el comunitarismo la ciudadanía constituye un vínculo originario y necesario de relación entre la comunidad y sus miembros. Esta concepción "hace de la ciudadanía el corazón mismo de nuestra vida" (Walzer,2001,162)

Por contra, desde premisas liberales, se concibe la ciudadanía como un concepto estrictamente político, es decir, como un vínculo que surge de la relación contractual (pacto social) y la adscripción libre de las personas con la sociedad (Rawls, 1993; 2001).

A partir de la Ilustración, la cultura y la política europeas se hallan abocadas a optar entre dos alternativas contrapuestas: la humanista liberal, de estirpe kantiana, que parte de la dignidad, la autonomía y la no instrumentalización de los hombres libres; y la tradición nacionalista, de signo herderiano, que concibe la nación o el pueblo como entidades colectivas naturales, dotados de espíritu propio, cifrado en esencias irracionales que trascienden los derechos de sus componentes. La acepción natural de la ciudadanía, hoy reivindicada desde premisas comunitaristas, tiene como presupuesto ideológico y se inscribe en la tradición nacionalista herderiana, mientras que la idea política de ciudadanía sustentada por el pensamiento liberal, tiene como antecedente el humanismo cosmopolita kantiano (Fernández García, 2001; Llano Alonso, 2002; Pérez Luño, 2002a).

\subsection{Global / local}

Se da también una marcada diferencia entre la versión global y local de la ciudadanía. La primera se halla sustentada en las elaboraciones doctrina- 
les que la conciben como el conjunto de todos los derechos fundamentales. Desde estas tesis, la ciudadanía es reputada como una noción omnicomprensiva, en la que se incluyen tanto los derechos personales, civiles y políticos, como los derechos económicos, sociales y culturales. Propugnó decididamente esta versión de la ciudadanía Thomas Marshall, en su conocida obra: Ciudadanía y clase social, en la que considera necesario no reducir la ciudadanía al ámbito estricto de la individualidad, sino ampliarla al conjunto de exigencias y necesidades de la persona en el desarrollo de su existencia como miembro de la colectividad. Marshall aboga por una "ciudadanía social" como alternativa y ampliación del concepto de "ciudadanía individual", forjada por la tradición del liberalismo conservador ( Marshall, 1998).

Frente a esta concepción, para un amplio sector de la doctrina iuspublicista, la ciudadanía posee una significación limitada. Debe quedar circunscrita a su sentido técnico-jurídico, que implica la determinación de la calidad de "ciudadano", es decir, al vínculo de pertenencia a una determinada organización política y a los derechos de participación democrática que de tal condición se derivan. Contribuyó a difundir esa tesis la Escuela alemana del derecho público y, en especial, Georg Jellinek, quien desarrolla esta doctrina en su célebre estudio sobre los derechos públicos subjetivos (Jellinek, 1964).

\subsection{Universal / particular}

La invocación a la ciudadanía amplía, en determinados planteamientos, su ámbito de referencia hasta hacerlo coincidir con un status universal . En estas versiones, de inequívoca impronta cosmopolita ligadas al proyecto humanista de la modernidad, se proyecta un modelo de ciudadanía que haga posible una universalis civitatis en la que se consagre plenamente el auspiciado status mundialis hominis. Esta acepción universalista y cosmopolita de la ciudadanía ha sido eficazmente reivindicada, en el plano filosóficopolítico por Martha Nussbaum (1999) y, en el plano jurídico constitucional, por Peter Häberle (1994; 1996. cfr. también: Fernández García, 2001; Llano Alonso, 2002; Pérez Luño, 2002a).

Son no obstante, más frecuentes las concepciones particulares de la ciudadanía. En la tradición doctrinal de Derecho público, se hace coincidir la idea de ciudadanía con la pertenencia a un Estado. Incluso en algunos estudios de Derecho municipal, se aboga por limitar, todavía más, el ámbito espacial de la ciudadanía. Desde estas ópticas de enfoque, se hace coincidir, en función de lo que su propia raíz terminológica evoca, la ciudadanía con la adscripción a la ciudad. Para este planteamiento, la ciudadanía quedaría preferentemente reducida a la esfera local, o sea, al sistema de relaciones 
políticas existentes entre la ciudad y sus ciudadanos. En los últimos años, se aprecia la tendencia a acentuar la vecindad civil como presupuesto básico para el ejercicio de los derechos cívicos (Rivero, 1993).

\subsection{Unilateral / multilateral}

Durante mucho tiempo, el uso lingüístico del término "ciudadanía” hacía referencia a un vínculo único y exclusivo entre el individuo y el Estado: se trataba, por tanto, de una relación unilateral y omnicomprensiva de toda la actividad política entre el individuo y el Estado. En las circunstancias de la hora presente, es posible admitir una pluralidad de ciudadanías, o sustituir la ciudadanía unilateral, por una ciudadanía multilateral. Esta última consistiría en ir más allá de una mera ciudadanía diferenciada (Kymlicka, 1996), en el interior del Estado. El reconocimiento del desbordamiento político y jurídico del Estado a través de los fenómenos de "supraestatalidad" (supeditación del Estado a organizaciones internacionales) y de "infraestatalidad" (asunción de competencias jurídico-políticas por entes menores que el Estado) (Pérez Luño, 1993), invita a admitir ese uso lingüístico multilateral de la idea de ciudadanía (vid. Infra n. 5).

Importa advertir que los distintos planos lexicales hasta aquí reseñados no agotan todos los usos lingüísticos del término "ciudadanía", aunque constituyen un inventario relevante de algunas de sus principales acepciones. Conviene también indicar que las distinciones analizadas en algunos de esos planos lexicales no entrañan necesariamente una oposición. Así, por ejemplo, la versión teórica de la ciudadanía no excluye su posible dimensión pragmática. Baste recordar, a tal efecto, el célebre opúsculo kantiano a tenor del cual una buena teoría lejos de ser una rémora para la práctica es su mejor garantía (Kant,1793). Otras distinciones, como la que hace referencia a las modalidades natural y política de la ciudadanía, expresan en sí mismas una contradicción irreductible. Asimismo, será posible establecer relaciones de complementariedad o contraposición entre las distintas acepciones incluidas en los distintos planos lexicales. El significado universal de la ciudadanía presenta íntima afinidad con la noción política de la misma, mientras que es incompatible con su acepción natural. También hay que hacer notar que aunque los distintos significados de uso de la ciudadanía operen en planos diferentes, ello no es óbice para que puedan acumularse coincidencias simultáneas entre algunas de esas distinciones. De este modo, es posible un uso lingüístico descriptivo de la ciudadanía que, al mismo tiempo, sea teórico, político, global, universal y multilateral. Si bien, lo más frecuente es que las coincidencias sean tan sólo episódicas y parciales. 
El mapa lingüístico de la ciudadanía deja abierta, en definitiva, la indagación de aquel o aquellos sentidos que deben considerarse más relevantes a los efectos de la investigación aquí planteada.

\section{Hacia una noción explicativa de la ciudadanía}

Si se desea no ver depotenciada la función jurídico-política de la ciudadanía, es preciso completar el análisis lexical de ese término con una indagación explicativa tendente a precisar su sentido y función. Las definiciones explicativas, en el seno de la teoría analítica, se utilizan cuando se trata de establecer el significado de conceptos que se hallan en los puntos claves de una cultura, sobre los que se condensan los planteamientos y orientaciones fundamentales constitutivos de la misma. Son nociones sobre las que se proyecta, principalmente, el quehacer filosófico y en las que es preciso atenerse a aquello que con esos conceptos se entiende; entrar en el corazón de su significado en la cultura histórica a la que pertenecen. Las definiciones explicativas pueden, a su vez, manifestarse a través de dos modalidades: la sistemática, que potencia el estudio lingüístico de los términos a partir de su análisis sintáctico, semántico y pragmático, así como su depuración de significaciones inútiles o confusas y la distinción de otras nociones análogas o afines; y la histórica, que indaga en la evolución diacrónica de los términos aquellos momentos y precedentes más decisivos para la conformación de su significado actual ( cfr. Pérez Luño, 2002b, 30 ss; id. 2002c, 49 ss.).

La definición explicativa de la ciudadanía entiendo que debiera elaborarse a partir de ambas modalidades, de modo que al explorarlas se evite incurrir en las polaridades de un dilema. Porque, si se pone el acento en una perspectiva sistemática, estrictamente analítica y sincrónica de la ciudadanía, quedaría amputada del significado actual de ese término la trayectoria evolutiva que explica su pleno sentido. Por contra, si se profundiza en ese insoslayable espesor histórico de la ciudadanía, se corre el riesgo de que el estudio se pierda en la noche de los tiempos, en la que cabe cifrar el origen remoto de ese concepto.

\subsection{Aproximación histórica}

No huelga recordar que la idea de ciudadanía evoca, en la Grecia clásica, la situación de la persona en la polis y constituye, por eso mismo, un elemento básico y originario de la propia noción de la política. La consabida definición aristotélica del hombre como "animal político", expresa esa simbiosis originaria entre la propia noción de humanidad y la pertenencia a la polis. Al margen de la política, es decir, de la participación en la vida de la ciudad, el individuo se ve desposeído de su personalidad humana y queda degradado a la condición de mera bestia (cfr. Fassò, 1959). El término "ciu- 
dadanía" procede etimológicamente del vocablo latino cives, que designa la posición del individuo en la civitas. La idea romana de ciudadanía hace referencia a un status integrado por un núcleo compacto e indesmembrable de derechos y deberes que definían la posición de las personas libres en la República. Marco Tulio Cicerón, en su celebre diálogo De republica, cifró en dos grandes pilares el fundamento y el nervio de las instituciones republicanas: la libertas y la concordia. La libertad consistiría en el desarrollo ordenado de la vida social garantizado por el ius civile; la ciudadanía representará, por tanto, la proyección de esa forma de libertad en las situaciones individuales (Cicerón, 51a.C).

Desde la perspectiva histórica, incluso se puede afirmar que la ciudadanía ha sido uno de los grandes motores de la historia. Así, junto a la concepción idealista de la historia, que la concibe como el producto del desarrollo y/o el conflicto de ideologías, creencias religiones... y la concepción materialista, que la reputa como el resultado de la lucha de clases, es decir, del enfrentamiento entre los poseedores y desposeídos de bienes económicos, cabría aludir a una tercera concepción del devenir histórico, que sería la consecuencia de la tensión entre la ciudad y el campo, entre las formas de vida rural y las formas de vida urbana. Cabe desprender esta tesis, por ejemplo, del radical enfrentamiento expuesto por Arnold Toynbee en su Estudio de la Historia (1970), entre las culturas forjadas por los pueblos nómadas y aquellas producidas por los pueblos sedentarios, las cuales serán las que, de un modo más decisivo, contribuirán al progreso de la civilización.

En la notoria obra sobre La ciudad antigua debida a Fustel de Coulanges (1996), se sostiene que la ciudad constituyó, desde la propia génesis de la evolución histórica de la humanidad, un reducto de seguridad, un espacio de comodidad y un estímulo de cultura. La ciudad representó, en efecto, una primera garantía de seguridad; más allá de los muros que delimitan su perímetro comienzan la incertidumbre y el peligro. La ciudad fue también un primer intento de organizar "la vida buena", por decirlo en la expresión aristotélica, o sea, la posibilidad de contar, aun de manera rudimentaria, con una serie de elementos (viviendas, vías y plazas, mercados, fuentes...) que contribuyen a hacer la convivencia más grata. La ciudad será también el núcleo embrionario de la civilización; la propia raíz etimológica de la civilización se halla, precisamente, en la noción de civilidad, es decir, en la vida cívica en cuya atmósfera debe situarse el orto del pensamiento, de la reflexión y de la deliberación racional sobre el mundo y la sociedad.

En la cultura islámica medieval, es digna de mención la obra sobre $L a$ ciudad ideal de Abu Nasr Al-Farabí (920). En esta obra se considerará, bajo la inequívoca impronta del idealismo platónico, a la ciudad como el compendio de todas las perfecciones de vida individual y social. Se retoma 
aquí la tesis platónica y aristotélica de la ecuación entre vida humana y vida cívica, porque al margen de la ciudad, expresión ejemplar de los designios divinos, sólo hay lugar para la barbarie y el salvajismo.

\subsection{Análisis sistemático: significación del término "ciudadanía" en el ámbito de la teoría jurídica y la doctrina constitucional}

La dimensión diacrónica hasta aquí esbozada resulta provechosa para indagar algunos momentos relevantes de la génesis conceptual de la ciudadanía. Pero, para captar su significado actual, esa exploración debe ser completada por un análisis sistemático. Dicho análisis tiene como punto de partida la etapa histórica en la que se conforma el uso lingüístico de la expresión "ciudadanía", en el que directamente se entronca su sentido presente.

La época en la que adquiere una significación nueva, directamente vinculada con un ejercicio efectivo de la libertad política, es la Ilustración. La ciudadanía será uno de los logros básicos del programa ilustrado de la modernidad; un factor decisivo en el proceso emancipatorio ligado a tal programa (Veca, 1990).

Nótese la coincidencia sincrónica entre la aparición del concepto moderno de la ciudadanía y la del propio concepto de los derechos humanos y del Estado de derecho, cuyo reconocimiento debe situarse también en el ámbito de la modernidad (Peces-Barba, 1982). La Revolución francesa será, ante todo, la revolución de los ciudadanos, y la cualidad de ciudadano pasará a ser, desde entonces, el centro de imputación del conjunto de derechos y libertades que corresponden a los miembros de un Estado de derecho.

Ciudadanía, derechos fundamentales y Estado de derecho no son sólo categorías jurídico-políticas que emergen en un mismo clima histórico, son realidades que se condicionan e implican mutuamente. El Estado de derecho es la forma política en la que los poderes actúan divididos y sometidos al impero de una legalidad que garantiza los derechos fundamentales de los ciudadanos. Los derechos fundamentales constituyen el fundamento de legitimidad del Estado de derecho y el contenido de la ciudadanía. La ciudadanía, a su vez, es el cauce de participación política en el Estado de derecho, a través del ejercicio de los derechos fundamentales (cfr. Pérez Luño, 2003, 212 ss.).

Para una definición explicativa de la ciudadanía, en clave histórica y sistemática, resultan de incuestionable valor algunos artículos políticos de la Enciclopedia debidos a Denis Diderot y Jean Le Rond d'Alambert. Esos textos representan una aportación emblemática de la cultura ilustrada y fueron un estímulo decisivo en la formación del Estado liberal de derecho.

Entre tales artículos, reviste particular interés, a los efectos de este estudio, la voz: ciudadano. En ella se define este concepto en términos concisos 
y rigurosos. Ciudadano: "es el miembro de una sociedad libre compuesta de muchas familias, que participan de los de esa sociedad" (Diderot y d'Alambert, 1751-1765, 16). De cuanto en este artículo, así como en el dedicado a la voz súbdito, se expresa, cabe derivar tres grandes principios de la idea de ciudadanía postulada por la Enciclopedia, en cuanto texto paradigmático de la modernidad ilustrada:

$1^{\circ}$ La ciudadanía es una condición de la persona que vive en una sociedad libre. En las ciudades o en las comunidades políticas donde impera el arbitrio o la tiranía no existen ciudadanos. Para que tal condición se dé, es preciso que se garantice un orden político democrático que permita el ejercicio de las libertades.

$2^{\circ}$ La ciudadanía es una condición voluntaria que no puede imponerse a ninguna persona. La cualidad de ciudadano se funda en el pacto social, en un acuerdo libre de las personas para integrarse y participar en un determinado modelo de organización política. Por ello, se postula en la Enciclopedia la existencia de un derecho natural a la emigración, porque a nadie se le puede obligar a ser ciudadano de un Estado por la fuerza. Toda persona tiene derecho al cambio de ciudadanía: a renunciar a la que posee para adquirir otra, que sea más acorde con sus convicciones y preferencias políticas. De ahí, que existan dos modalidades de ciudadanía: la originaria, que surge con el nacimiento, y la adquirida, que procede de manifestaciones expresas de voluntad.

$3^{\circ}$ La ciudadanía se desglosa en un conjunto de derechos y deberes de las personas que pertenecen a un determinado Estado. Conviene advertir, que según se indica expresamente en la enciclopedia, no todas las personas son ciudadanos, puesto que las mujeres, los niños y los siervos no poseen tal condición; participan de ella a través de los vínculos que les unen con quienes ostentan la condición de ciudadanos (Diderot y d'Alambert, 17511765,16 ss. y 225 ss.).

No sería lícito omitir la contribución de Immanuel Kant a la génesis doctrinal del concepto de ciudadanía, como un ingrediente insoslayable de su propia contribución al orto de la idea del Estado de derecho. Kant señala expresamente que: "La situación de los ciudadanos, considerada como situación puramente jurídica, se funda en los siguientes principios a priori:

1. La libertad de cada miembro de la sociedad, como hombre (Die Freiheitjedes Gliedes der Societät, als Menschen).

2. La igualdad de él mismo frente a cualquier otro, como súbdito (Die Gleichheit desselben mitjedem andern, als Untertan).

3. La independencia de cada miembro de la comunidad, como ciudadano (Die Selbstündigkeit jedes Gliedes eines gerneinen Wesens, als Bürger). 
Estos principios -explica Kant- no son leyes ya dadas por un Estado instaurado, sino leyes que por sí hacen posible la constitución del Estado según los principios de la pura razón (reinen Vernunfiprinzipien) que emanan del derecho externo del hombre" (Kant, 1793, 289-290).

El planteamiento de Kant corrobora la continuidad existente entre las nociones de derechos, Estado de derecho y ciudadanía. En el texto precitado, se hace del ciudadano portador de derechos y libertades universales, por su mera condición de ser humano. Kant sostiene, asimismo, la garantía de la igualdad de cada ciudadano con los restantes miembros del cuerpo social, con la consiguiente abolición de privilegios y situaciones estamentales, en cuanto súbdito del Estado. Debiendo advertirse que, en este fragmento, el término "súbdito" no posee la connotación peyorativa de sometimiento a un poder despótico, sino el sentido descriptivo de vinculación del ciudadano al Estado. Por último, Kant alude a un significado específico de la cualidad de ciudadano: su independencia. Esa facultad debe entenderse como un poder para la participación libre en la vida política (cfr. Pérez Luño, 2001, 458 S.)

De los textos de la enciclopedia y de las tesis kantianas, se infieren determinadas premisas que permiten avanzar en el proceso definitorio explicativo. La ciudadanía, consistirá en el vínculo de pertenencia a un Estado de derecho por parte de quienes son sus nacionales, situación que se desglosa en un conjunto de derechos y deberes; ciudadano será la persona física titular de esa situación jurídica.

En esa doctrinas, aunque se destaca la importancia del derecho a la participación política como uno de los principales atributos de la condición de ciudadano, no se establece una distinción cualitativa de tal derecho respecto al conjunto genérico de derechos y deberes que conforman la noción de ciudadanía. Corresponde a la Escuela alemana del derecho público y, en particular, a Georg Jellinek, el haber contribuido, de forma decisiva, a perfilar la distinción entre: la ciudadanía en sentido genérico (status civitatis ), que comprende el conjunto de derechos públicos subjetivos de los ciudadanos; y el sentido estricto de la ciudadanía (status activae civitatis), que hace inmediata referencia a los derechos políticos. Entre tales derechos destacan los de sufragio activo y pasivo, es decir, aquellos derechos regulados por el ordenamiento jurídico que facultan a los ciudadanos para ser electores y elegidos en los procesos democráticos que contribuyen a la formación de la voluntad política del Estado. La condición de ciudadano implica, por tanto, un protagonismo activo en el curso y la determinación de la política estatal (Jellinek,1964, 81 ss. vid. también lo expuesto supra en el apartado 2.4.).

El ulterior desarrollo de la doctrina iuspublicista, así como el del constitucionalismo de los Estados de derecho, han confirmado la versión estricta 
y técnico-jurídica de la ciudadanía. Dicha noción expresa, en la actualidad, el vínculo de pertenencia a un Estado de derecho, concretado en el derecho a la nacionalidad y en los derechos de participación política que de esa condición jurídica se derivan.

\section{La crisis de la ciudadanía}

La concepción ilustrada de la ciudadanía informó los procesos revolucionarios burgueses, que determinaron la consagración de esta categoría jurídico-política en los Estados de derecho liberales. En ellos, la ciudadanía tuvo sus luces y sus sombras. De una parte, fue un instrumento básico para la emancipación jurídica y política de quienes gozaron de la condición de ciudadanos; de otra, supuso una práctica discriminatoria en la titularidad y el ejercicio de tal condición.

Karl Marx mostró, desde sus escritos juveniles, una preocupación constante por afrontar desde una actitud crítica las contradicciones internas de la concepción burguesa de la ciudadanía. Así se desprende de su célebre crítica a la escisión que delata la Declaración revolucionaria francesa de 1789 entre los derechos del hombre y los del ciudadano. En el trabajo Zur Judenfrage (sobre la cuestión judía) analizará las consecuencias que entraña distinguir los derechos del hombre, entendidos como derechos del individuo egoísta, del burgués en cuanto miembro de la sociedad civil (bügerliche Gesellschaft), y los derechos del ciudadano (Staatsbürger) de la comunidad política que los ejerce participando en la vida social con los demás miembros de la misma (Marx, 1843, I, 362 ss.).

De este modo, se denuncia una fractura entre el hombre como individuo, cuyas posibilidades de actuación en la sociedad civil se hayan condicionadas por el desigual reparto de los bienes, y el ciudadano como sujeto titular de relaciones formalmente iguales en el seno de la comunidad política. Marx propugna la superación de esa fractura al concebir los derechos humanos como derechos políticos en cuyo ejercicio el hombre no sea una mónada aislada, sino un miembro que participe solidariamente con sus conciudadanos en las formas de la comunidad política (politisches Gemeinwesen ). La realización de los derechos humanos exigía, según Marx, una emancipación humana que se produce cuando el hombre y el ciudadano se funden; esto implica el reconocimiento y organización de sus propias fuerzas como fuerzas sociales y, por tanto, no separar de sí mismo la fuerza social bajo la forma de la fuerza política (Marx, ibíd.).

Se infiere de la crítica de Marx que la ideología burguesa había traicionado los ideales revolucionarios de la tricolor: Marx considera que la ciudadanía en su concepción burguesa, constituye una exaltación del egoísmo; implica una visión atomista del individuo, como una mónada aislada del 
resto de los miembros de la comunidad a la que cada persona pertenece. La práctica burguesa de la ciudadanía desconoce que todos los hombres forman parte de la especie humana. Por eso, la autenticidad liberadora de la ciudadanía burguesa se vio desmentida. En las primera etapas del Estado liberal, subsistieron profundas desigualdades entre los seres humanos, que impedían un ejercicio real y efectivo de la libertad a quienes se hallaban desposeídos de bienes económicos. En su crítica a la concepción de la ciudadanía burguesa, Marx fue, incluso, indulgente. Porque la discriminación de los sujetos no se producía sólo en su condición de "hombres", es decir, en la esfera de las relaciones económicas, sino también en el plano político y formal, en el que Marx admite la igualdad de los "ciudadanos" en cuanto miembros de la comunidad política. El Estado liberal-burgués, como es notorio, negaba el pleno ejercicio de la ciudadanía y discriminaba jurídicamente a las mujeres, a los analfabetos y a los pobres (sufragio censatario).

En una etapa posterior, más próxima a nuestra época, aparece en el año de 1949 la obra de Thomas Marshall Citzenship and Social Class, que supone una abierta crítica a la teoría y la práctica liberal-individualista de la ciudadanía. Marshall aboga por una ampliación del concepto de ciudadanía. Esta noción, a su entender, no debe quedar limitada a la titularidad de los derechos políticos, tal como era asumida por las doctrinas iuspublicistas. Como alternativa, propugna una ciudadanía concebida como status de miembro de pleno derecho de una comunidad. De ello se desprende que para Marshall, el alcance de la ciudadanía no quede circunscrito al plano "individual", de la mera titularidad de derechos políticos, sino que comprenda una dimensión "social" concretada en el disfrute de los derechos y garantías sociales, económicos y culturales ( Marshall, 1998, 85 ss.).

La propuesta de Marshall tendente a un concepto global de ciudadanía (vid. supra 2.4), como centro de imputación de todos los derechos y deberes del sujeto de una comunidad política, no supone ninguna innovación. Esta versión genérica de la ciudadanía cuenta, como se ha expuesto (vid. supra 3.1), con una larga tradición histórica. De ahí, que aunque no exista inconveniente en admitir, lato sensu, esa acepción, debe advertirse que en su significado explicativo más riguroso, la ciudadanía expresa la condición de titular de los derechos de participación política.

La obra de Marshall tuvo el mérito de abrir un amplio debate de revisión y de crítica de la noción liberal de ciudadanía. Sus tesis han sido, junto con otras doctrinas y circunstancias que ahora serán analizadas, un factor relevante en la actual coyuntura de controversia y crisis del modelo teórico de ciudadanía. 


\subsection{El debate sobre la participación política en el Estado social de derecho}

En la misma etapa, e incluso, en determinados supuestos, en fecha anterior a la aparición de la obra de Marshall, algunas de las voces más representativas en la teorización e impulso del Estado social de derecho habían contribuido a plantear abiertamente la nueva dimensión de la ciudadanía implícita en el tránsito del Estado liberal a ese nuevo modelo social de Estado de derecho.

Esa fue la actitud de Hermann Heller, uno de los más prestigiosos y decididos teóricos del Estado social de derecho, quien dirá que frente a las dictaduras totalitarias y a la nomocracia (Nomokratie) en que desemboca la concepción formalista kelseniana, el Estado social de derecho debe suponer, como respuesta a las demandas de democracia social del proletariado, "la extensión del pensamiento del Estado de Derecho material al orden del trabajo y de los bienes (die Ausdehnung des materiellen Rechstsstaatsgedankens auf die Arbeits-und Güterordnung)"(Heller, 1978, I, p. 165).

En Italia, el pensador y político socialista Lelio Basso, a cuyo empeño se debe el art. 3.2 de la Constitución italiana de 1947 en el que se inspira el art. 9.2 de la Constitución española de 1978, reivindicó el nuevo concepto de ciudadanía que dimana del Estado social de derecho. En su libro Il principe senza scettro (Basso, 1958), sostiene el compromiso democrático y emancipatorio del Estado social y llega a afirmar que en dicha forma política cada ciudadano debiera ser partícipe de cuotas concretas de poder. En tales circunstancias, cada ciudadano podría decir, con estricto rigor de verdad: "el Estado soy yo". El ciudadano del Estado social de derecho sería la versión democrática alternativa a la imagen del autócrata Luis XIV.

Este ambicioso programa emancipatorio no ha podido alcanzar plenamente sus objetivos. El Estado social de Derecho que había legitimado su omnipresente intervencionismo en función de un amplio catálogo de medidas de bienestar, se halla hoy desbordado por sus propios compromisos; siendo esa una de las principales causas de su crisis como modelo político.

La falta de respuesta estatal a las exigencias sociales, la demora con la que las más apremiantes son atendidas contribuyen a crear un clima de inseguridad en la eficacia de la respuesta política a las aspiraciones y necesidades de la ciudadanía. Con la penetración que le distingue, Norberto Bobbio denuncia la instrumentalización de la ineficacia estatal por parte de grupos subversivos para intentar resolver por la fuerza los problemas que las disfunciones del sistema democrático dejan sin solución: "La tendencia a resolver los conflictos con la fuerza conduce a la gradual suspensión de algunas normas características del Estado de derecho; el deterioro del Esta- 
do de derecho agrava la crisis de la democracia dando lugar a un auténtico y real círculo vicioso" (Bobbio, 1985, 13).

Conviene advertir que la crisis de legitimidad que entraña para el Estado de derecho su incapacidad para responder adecuadamente a las demandas sociales no debe entenderse como una legitimación de las acciones de las bandas terroristas. La circunstancia negativa de que el Estado de derecho haya sido incapaz de llevar a la práctica el programa emancipatorio de la Modernidad, reforzado en sentido democrático por el Estado social de derecho, no debe inducir al error de difamar los postulados de la Ilustración al identificarlos con una "razón terrorista". "Quien confunde el proyecto de la Modernidad -escribe Jürgen Habermas- con la conciencia y los actos públicos y espectaculares de los terroristas aislados comete el mismo error de visión que quien sostiene que el terror burocrático, cada vez más intenso y extenso, que se ejerce en la oscuridad, en las celdas de la policía militar y secreta, en los establecimientos psiquiátricos, es la raison d' etre del Estado moderno ( y su dominación jurídica vaciada por el positivismo) únicamente porque dicho terror se sirve de los medios coactivos del aparato estatal" (Habermas, 1988, 279).

En esas coordenadas, que definen la actual instalación de las relaciones humanas públicas y privadas, el discurso sobre la ciudadanía registra un nuevo cambio de rumbo. El proyecto ilustrado de la modernidad tendió a "liberar del privilegio y de la opresión la vida política colectiva, asegurando la igualdad formal de los ciudadanos". El Estado social de derecho, en cuanto prolongación en clave emancipatoria de los ideales ilustrados, pretendió remover los obstáculos y desequilibrios económicos que se oponían a un disfrute de la libertad por parte de todos los ciudadanos, promoviendo su igualdad real (Pérez Luño,1981; 1985).

Hoy juristas, economistas y filósofos, de diversas culturas lingüísticas e idéntica observancia conservadora, se inclinan ficticiamente compungidos sobre lo que ellos consideran como el cadáver del Estado social de Derecho y la condición de la ciudadanía surgida en su seno, que ellos no han engendrado ni nutrido. Las leyes infalibles del mercado son, a tenor de estas tesis, el síntoma y la causa de la defunción. Pero frente a ese determinismo fatalista de signo economicista hay que recordar que las leyes económicas no son leyes físicas producto de una causalidad ineluctable, sino leyes creadas por los hombres que sirven a fines humanos. "El mercado no es un Moloch intocable e inflexible; -en palabras de Francisco Contreras- el mercado es una hipóstasis, una abstracción... bajo la que se esconde simplemente una pluralidad de voluntades humanas, voluntades que pueden ser modificadas y que pueden llegar a acuerdos" (Contreras Peláez, 1994,99). 
El Estado social de derecho supuso, en definitiva, una forma más justa de ejercer la ciudadanía. La quiebra de alguno de sus logros (pleno empleo, plena garantía de la educación, sanidad y servicios asistenciales...), permite hoy valorar en su auténtica dimensión el avance emancipatorio que, pese a sus insuficiencias y límites, supuso en las sociedades de bienestar el Estado social. Ello muestra la unilateralidad y ofuscación de aquellas críticas del radicalismo de izquierdas que descalificaban al Estado social, al considerarlo como un mero gestor de los intereses capitalistas y un mecanismo para domesticar al movimiento obrero. El sarcasmo es todavía mayor cuando se proyecta sobre países subdesarrollados que asisten hoy a la quiebra de un Estado social cuyos beneficios no alcanzaron a disfrutar; es más, en el seno de muchos países del tercer mundo, la propia dimensión liberal de la ciudadanía sigue siendo una promesa aplazada.

\subsection{La fragmentación de la ciudadanía}

El orto del concepto moderno de ciudadanía se halla ligado, como se ha tenido ocasión de exponer supra, a la noción de nacionalidad; ser ciudadano, equivalía en el Estado liberal de derecho a ser nacional del Estado. En las sociedades complejas y plurales de nuestro tiempo, cuyos Estados engloban fenómenos más o menos amplios e influyentes de multiculturalidad y multinacionalidad, la ecuación ciudadano=nacional ha quedado desvirtuada. El nuevo ámbito de ejercicio de la ciudadanía es, por ello, mucho más complejo que en épocas anteriores y ello ha repercutido en la propia necesidad de revisión de su concepto.

En la coyuntura del presente, han surgido una serie de posturas teóricas aunadas por el propósito común de denunciar la insuficiencia del concepto tradicional de ciudadanía. La apelación a una "ciudadanía fragmentada" puede considerarse como el síntoma más evidente de esa crisis que invocan los detractores de la idea moderna de esa categoría conceptual. Considera causa inmediata de esa crisis el papel que históricamente incumbe a la ciudadanía de: "cumplir -en palabras de Fariñas Dulce, que compendian estos enfoques- una función de integración social, jurídica y política de los individuos supuestamente semejantes en estructuras universales y homogeneizadoras". Se imputa, desde esas premisas la noción de ciudadanía gestada en la modernidad de ser responsable de: "homogeneizar ficticia e intolerantemente, a todos los individuos en un estatus común y universal de ciudadano" (Fariñas Dulce, 2000, 36-37).

En las doctrinas críticas actuales contra la versión liberal / ilustrada de la ciudadanía, ha asumido un protagonismo relevante, hasta el punto de ser constantemente invocada por los multiculturalistas, la obra de Will Kymlicka. De conformidad con su planteamiento, en las grandes sociedades 
complejas del presente, integradas por colectividades multiraciales, multicuturales y plurilingüísticas, y culturas diversas que conforman la comunidad internacional, propugna el reconocimiento de la diversidad cultural como fundamento de una diferenciación de los ciudadanos. Kymlicka defiende un concepto de "ciudadanía diferenciada", que se haga cargo de la diversidad de valores culturales que se dan en el seno de los grandes Estados de las sociedades desarrolladas de nuestro tiempo. En ellas, la población se halla integrada por una multiplicidad de grupos, que ostentan acusados rasgos identitarios peculiares que marcan notables divergencias. La población de las sociedades democráticas del presente ha dejado de ser la imagen abstracta de un todo compacto e indiviso, para mostrar su realidad compleja y heterogénea (Kymlicka, 1989; 1996; 2003).

Kymlicka, que proclama su deseo de revisar la concepción liberal de la ciudadanía desde el propio liberalismo, asume determinadas tesis que poseen una evidente impronta comunitarista. El comunitarismo, como se tuvo ocasión de indicar supra (apartado 2.3), se opone a una visión convencional, abstracta y desarraigada de la ciudadanía, tal como, según sus partidarios, habría sido forjada por el liberalismo en la modernidad. En definitiva, el comunitarismo situaría el fundamento de la cultura en la identidad homogénea comunitaria que se expresa en el ethos social, es decir, la Sittlichkeit, como alternativa a la universalidad abstracta del racionalismo ilustrado moderno. Sin referencia a la comunidad cultural o étnica a la que cada sujeto pertenece, la ciudadanía será un concepto ideal y abstracto, porque es cada comunidad histórica la que va a dotar de unos perfiles específicos y concretos a los vínculos de pertenencia de cada persona con su comunidad, en los que se expresa de forma "natural y necesaria" la ciudadanía ( Kymlicka, 1989, 76 ss.; id. 1995, 219 ss 2003, passim; cfr.: De Castro, 1995, 399 ss.; Contreras Peláez, 1998, 69 ss.).

Will Kymlicka postula un planteamiento de la ciudadanía que pretende ser una versión de síntesis de ingredientes liberales y comunitaristas. Acogiendo premisas de estos últimos, defiende lo que denomina "protecciones externas" de las minorías étnicas o culturales, cuyos rasgos identitarios deben ser objeto de una política de reconocimiento y tutela por parte del Estado donde se hallan integradas. Pero, sensible a la tradición liberal, es consciente de que se deben salvaguardar también los derechos de los individuos integrados en tales minorías, frente a las "restricciones internas" invocadas "en nombre de la tradición cultural o la ortodoxia religiosa" de los grupos.

El orden político de los Estados de derecho liberales es abiertamente incompatible con la posibilidad de que en su seno se niegue la autonomía y la libertad de pensamiento, de crítica y de decisión de las personas en nombre de la solidaridad grupal o de su pertenencia a comunidades que por su 
radicalismo étnico, religioso o ideológico nieguen esos derechos humanos básicos (Kymlicka, 1996, 59 ss.).

Reconoce Kymlicka que no siempre es fácil trazar esa distinción entre restricciones internas y protecciones externas. Determinadas medidas de protección externa de algunos grupos, pueden implicar graves restricciones internas a la libertad y autonomía de los individuos pertenecientes a dichas comunidades. Cita el caso de la política lingüística desarrollada por el Estado Canadiense en Québec. En este territorio, la protección externa de la comunidad francófona ha supuesto limitaciones para la libertad lingüística de los individuos que forman parte de tal comunidad (Kymlicka, 1996,68 ss.; 2003, 196 ss.). Incidiendo en esa dificultad, denuncia Francisco Contreras Peláez la situación, a su entender (que plenamente comparto) todavía más inquietante, de cuanto ocurre en España con la política de "inmersión lingüística" impuesta por la Generalidad catalana. "Los derechos individuales de los castellano-hablantes... son gravemente vulnerados, con la excusa de la defensa de la identidad cultural catalana frente a una fantasmal presión uniformizadora, supuestamente ejercida por el resto de España”. Esa política ha producido: "la progresiva erradicación del idioma español del sistema escolar catalán (y el consiguiente desconocimiento del derecho de los niños castellano-hablantes a ser educados en su lengua materna)"(Contreras Peláez, 2001, 141-142; vid., también, De Carreras i Serra, 1999, 130 ss.).

Los riesgos que en la vida política práctica pueden derivarse de la tesis de Kymlicka, determinan que su propuesta de ciudadanía diferenciada resulte muy cuestionable. Si con ella se pretende garantizar el respeto a las minorías en un sistema de pluralismo, de tolerancia y de tutela de los derechos individuales, no se advierte en ella ningún avance cualitativo respecto a lo que entraña la noción liberal de ciudadanía. Si lo que persigue es dotar a las comunidades culturales o étnicas de unos supuestos "derechos colectivos" propios, cifrados en pretendidas esencias identitarias, entonces los derechos de ciudadanía de los individuos integrados en tales comunidades, y en concreto su autonomía y la libertad individual, pueden quedar seriamente limitados e, incluso, vacíos de contenido.

En la filosofía del derecho española actual, las tesis de Kymlicka han hallado notable eco. Entre quienes más decididamente han contribuido al estudio y difusión de su propuesta de "ciudadanía diferenciada" ocupa un lugar destacado Javier de Lucas. Asumiendo algunos planteamientos básicos de Kymlicka, así como determinadas doctrinas multiculturalistas, De Lucas revisa el concepto liberal de ciudadanía, al que reprocha su carácter ideal y abstracto, incapaz de hacerse cargo de las realidades diferenciales y utilizado como instrumento para la exclusión de su disfrute a determinadas 
minorías. De entre los argumentos aducidos en pro de este empeño intelectual, entiendo que pueden destacarse los siguientes:

1) La identificación del concepto liberal de ciudadanía con el Estado nacional. De Lucas denuncia el concepto de ciudadanía liberal, a su entender, basado en la el vínculo político de pertenencia al "Estado Nacional, en el que Nación, Estado y cultura son uno, como consecuencia de compartir los lazos de origen, tradición, prácticas e instituciones culturales surgidas de forma análoga a la que caracteriza las estructuras de parentesco, es decir, la sangre y la tierra, según el esquema del nacionalismo romántico encarnado en la conocida fórmula Blut und Boden que a su vez daría pie al principio de ius sanguinis como título de nacionalidad y ciudadanía” (De Lucas, 2002, 16).

2) Atribución al liberalismo de un concepto (natural) de ciudadanía y, al propio tiempo, "ideal" y "abstracto". Javier de Lucas ofrece una lectura del concepto liberal de ciudadanía en el que ésta aparece como una categoría "natural", cifrada en vínculos necesarios surgidos de la propia "homogeneidad nacional" $(2002,12)$. Pero al propio tiempo, sustenta el carácter ideal y abstracto de la ciudadanía liberal edificada sobre el "sofisma" del universalismo ilustrado. De conformidad con ello, para ser reconocidos como seres humanos y, en consecuencia como ciudadanos, "tendríamos que despojarnos de todas las características concretas personales e históricas sobre las cuales existe la persona". La tolerancia desde categorías políticas construidas a partir de esos parámetros liberal-ilustrados, le parecen a De Lucas "autodestructiva, porque obliga a perder al ser humano real, desde la base de que el puro homo noumenico puede constituir una comunidad" (2002,14-15).

3) Denuncia de la crisis de legitimidad del concepto liberal de ciudadanía. Afirma De Lucas que si el Estado liberal "no toma en serio las minorías", sus instituciones políticas adolecerán de un déficit de legitimidad democrática. Por tanto, una ciudadanía forjada al margen de las exigencias de reconocimiento identitario de las minorías nacionales, étnicas o lingüísticas "afectan a la legitimidad democrática en sociedades multiculturales" $(2002,19)$.

Las tesis de De Lucas poseen la virtualidad de asumir en síntesis algunos de los argumentos más recurrentes de las críticas comunitaristas y multiculturalistas contra la noción liberal de ciudadanía. Tales críticas, estimo que inciden en algunas confusiones y descuidan hechos notorios. Frente a ellas pueden avanzarse algunas reservas que, en lo que atañe a la postura de mi compañero y amigo Javier de Lucas, llevan implícitas esa dosis de reconocimiento y homenaje que son la otra faceta de la discrepancia intelectual. 
1) En lo referente a la identificación entre la idea liberal de la ciudadanía y el Estado nacional, habrá que matizar que el Estado de derecho liberal no puede asimilarse al Estado-Nacionalista. El concepto de Nación que subyace a estas dos formas de Estado es, no sólo distinto, sino contrapuesto. El Estado liberal parte del modelo de Nación / contrato, es decir, la nación es fruto del acuerdo de sus integrantes sobre tradiciones, valores y sentimientos compartidos; mientras que para el nacionalismo rige el modelo de Nación / status étnico, o sea, que tal categoría constituye una entidad colectiva "natural", dotada de espíritu propio, cifrado en esencias irracionales que trascienden los derechos de sus componentes. Existe por tanto, una abierta y radical antítesis entre el Estado liberal y el Estado nacionalista, porque todo nacionalismo representa una exaltación de determinados rasgos identitarios nacionales que se postulan como ideología omnicomprensiva o cosmovisión política, premisas que son incompatibles con el liberalismo. No deben confundirse, por eso, el Estado de derecho propio de las sociedades liberales con los fenómenos nacionalistas totalitarios y excluyentes. La alusión al mito de la "tierra y la sangre", así como a todas las supuestas homogeneidades identitarias basadas en la raza, la lengua, o el "espíritu del pueblo", fueron en el pasado y son hoy invocadas por los nacionalismos que pugnan por abolir o menoscabar las garantías de libertad y autonomía propias del Estado de derecho liberal.

2) Parece una contradicción evidente atribuir al liberalismo una concepción "natural" de la ciudadanía y, al propio tiempo, considerarla como una convención política "ideal" y "abstracta" propia de "hombres nouménicos". No huelga recordar que la concepción natural de la ciudadanía es aquella, que como se ha tenido ocasión de exponer supra, propugnan los comunitaristas (2.3), quienes reprochan a la concepción liberal la defensa de un concepto de ciudadanía basado en convenciones políticas. Ese carácter contrafáctico y normativo de la ciudadanía liberal, tal como fue postulada kantianamente para "hombres nouménicos", representó una necesidad histórica (cfr. Fernández García, 2001; Llano Alonso, 2002; Pérez Luño y Contreras Peláez, 2001). En la génesis del Estado liberal, los "hombre fenoménicos" se hallaban integrados y hasta absorbidos por estamentos, gremios, glebas, corporaciones territoriales y otros entes colectivos que determinaban la negación de su libertad, de su autonomía y de su propia individualidad. La noción moderna de ciudadanía, propia del Estado liberal, supuso la emancipación política de los individuos, al sustituir sus vínculos políticos necesarios, desiguales, cerrados y naturales, por un vínculo político basado en el pacto social que garantizaba la libertad política en términos de ciudadanía. La ciudadanía moderna y liberal es el símbolo emblemático de la participación política en las sociedades abiertas. De ahí, que determinadas 
pretensiones comunitaristas o multiculturalistas de la postmodernidad, lejos de suponer un avance emancipatorio, implican una regresión a fórmulas propias de la sociedad estamental. Tiene plena razón Giovanni Sartori cuando indica que: "abolida la servidumbre de la gleba que ligaba al campesino con la tierra, hoy tenemos el peligro de inventar una servidumbre de la etnia" (Sartori, 2001,105).

3) En lo tocante a "tomar en serio las minorías", estimo que es un propósito que debe ser objeto de cumplimiento estricto. Ello equivale a asumir con las debidas dosis de objetividad y rigor el papel real de las minorías culturales en el Estado de derecho. Porque, para que exista un conflicto entre minorías culturales en el seno de un Estado liberal, es necesario que éstas se conciban como "bloques de creencias monolíticas e inamovibles". Esta idea conflictiva de las culturas, en palabras de Elena Beltrán Pedreira, "es difícil de sostener, entonces los conflictos no son conflictos entre culturas, sino entre individuos que sostienen creencias diferentes a las creencias de la mayoría y el Estado o sus instituciones, en cuyo caso las reglas del juego democrático, el respeto a los derechos y a la dignidad de las personas más el debate cívico marcan las líneas a seguir" (Beltrán Pedreira,2002, 404; en el mismo sentido, Laporta, 2001). Tampoco puede omitirse el fenómeno de falsificación de numerosas identidades culturales, las cuales "se fabrican, o incluso se resucitan a propósito, sin suficientes buenas razones para hacerlo" (Sartori, 2001, 126). Todavía es más tajante Contreras Peláez cuando se refiere a la impostura a que responden determinadas reivindicaciones de minorías culturales: "son postizas las comunidades imaginarias, las tradiciones inventadas o artificiosamente resucitadas, las culturas soñadas por comunitaristas y multiculturalistas...”(2001, 154).

Suscribo, no obstante, sin reservas la crítica planteada por De Lucas a la noción puramente nominal y depontenciada de eficacia de la ciudadanía, así como su denuncia a la instrumentalización de la ciudadanía para excluir a determinadas personas o grupos de su disfrute. Alude, de forma expresa, al uso excluyente que de tal categoría realizan determinados estados de derecho liberales, para marginar del acceso a los derechos a extranjeros e inmigrantes ( De Lucas, 1992; 1994). En esta denuncia tiene tanta razón que hasta parece demasiada. Por eso mismo, la coherencia lógica, el correcto uso de la hermenéutica jurídica y la solidaridad ética invitan a proyectar ese enfoque a las situaciones de exclusión, marginación o desprotección de aquellos ciudadanos sometidos a políticas nacionalistas. En esas comunidades, los poderes políticos nacionalistas imponen el régimen de monopolio, una visión cerrada y omnicomprensiva de la identidad nacional y del vínculo de pertenencia política. Estos nacionalismos que, en determinados ámbitos se muestran insensibles e incluso justifican la violencia contra los insumisos al 
credo nacionalista, son responsables del exilio interior y de la sensación de ser extranjeros en su propia tierra de muchos ciudadanos, cuyo disfrute de tal condición queda degradada a un mero flatus vocis.

Quizás, para poner las cosas en términos cuerdos, cabría propugnar un "uso alternativo" por parte de los liberales de los argumentos utilizados por las versiones de signo más radical comunitarista o multiculturalista, entre las que no se inscriben las tesis de Kymlicka y De Lucas. De este modo, se podría denunciar la opresión e intolerancia que las minorías nacionalistas que alcanzan el poder político ejercen contra quienes, en el seno de tales comunidades, discrepan de la homogeneidad identitaria nacional; aduciendo las "restricciones internas", en el sentido empleado por Kymlicka. La experiencia de algunos de los Estados surgidos en Europa tras el desmoronamiento del bloque del Este, como fruto de la reivindicación nacionalista de pueblos anteriormente oprimidos, muestra la falta de respeto de esos nuevos Estados hacia los derechos de las minorías étnicas subsistentes en su seno (Habermas, 1989; 1997).

\subsection{La negación de la ciudadanía}

En las últimas décadas se ha formulado una profunda revisión crítica del concepto de ciudadanía. La crisis de la denominada "ciudadanía social", y la fragmentación de la idea de ciudadanía, propugnada por comunitaristas y multiculturalistas han desembocado en posturas que se plantean la propia abolición de ese concepto.

Entre las posturas teóricas que impugnan la persistencia y razón de ser actual de la noción de ciudadanía, destaca la argumentación debida a Luigi Ferrajoli. En algunas de las últimas publicaciones del profesor de la Universidad de Camerino, ocupa un lugar destacado su inequívoca propuesta de superación de la idea de ciudadanía, al considerarla no sólo inadecuada desde el punto de vista de la teoría jurídica, sino responsable de prácticas políticas indeseables.

Ferrajoli parte de la crítica a Thomas Marshall y a su intento de ofrecer una versión omnicomprensiva de la ciudadanía, que como se ha tenido ocasión de exponer supra (4.1), englobaba los derechos civiles y políticos, así como los derechos sociales. Esa concepción propugnada por Marshall era responsable, en opinión de Ferrajoli, de haber enturbiado el significado estricto de la ciudadanía como un status subjetivo para la titularidad de los derechos políticos, hasta hacerlo coincidir con la titularidad de todos los derechos de la personalidad (Ferrajoli, 1999, 97ss; 2001, 40 ss.). Para evitar confusiones y una ampliación excesiva de los derechos de ciudadanía, incompatible con su acepción jurídica, propugna Ferrajoli: "evitar caer en posiciones iusnaturalistas y formular algo más que meras filosofías de la jus- 
ticia: los derechos no pueden ser más que lo que los distintos ordenamientos establecen en cada lugar y en cada época" (1999, 97-98).

Desde la Declaración de derechos de 1789 de la Revolución francesa, se produce una disociación entre el hombre y el ciudadano. A partir de ese texto existirán dos tipos de derechos fundamentales: "los derechos de la personalidad, que corresponden a todos los seres humanos en cuanto individuos o personas, y los derechos de ciudadanía, que corresponden en exclusiva a los ciudadanos" (Ferrajoli, 1999, 99). Englobar en una única categoría a los "derechos del hombre y del ciudadano", a partir de una "noción genérica y amplia de ciudadanía”, según la propuesta de Marshall, le parece a Ferrajoli una idea contrapuesta a la evolución actual de los derechos (Ferrajoli, 1999, 99-100; 2001, 42-43). La Declaración universal de los derechos humanos de la ONU de 1948, así como el constitucionalismo democrático contemporáneo, han convertido a la "persona" en sujeto titular de derechos universales, frente al "ciudadano", que circunscribía los derechos a una relación del Estado con sus individuos. La propia erosión de la soberanía estatal, motivada por las tendencias supranacionales del presente, así como la exigencia de la dignidad e igualdad de todos los hombres que garantice no sólo sus derechos individuales, sino también los de naturaleza económica y social, determinan la necesidad de sustituir los derechos de ciudadanía por los derechos de la personalidad.

En función de estos argumentos, Luigi Ferrajoli concluye denunciando el carácter discriminatorio que hoy lleva aparejado el recurso a los derechos de ciudadanía. En una época en la que el problema más grave y urgente de las sociedades democráticas es el de dar una respuesta justa a los crecientes flujos migratorios que penetran en sus fronteras, la ciudadanía es utilizada como instrumento para negar derechos y libertades a los inmigrantes y asilados. De ahí, que Ferrajoli propugne: "la superación de la ciudadanía, la definitiva desnacionalización de los derechos fundamentales y la correlativa desestatalización de las nacionalidades". Se trata en suma, de tomar consciencia de la "crisis irreversible"de la vieja noción de la ciudadanía y de certificar su completa abolición (Ferrajoli, 2001, 43-44).

La implacable descalificación del concepto de ciudadanía que se desprende de las críticas de Ferrajoli, estimo que debe ser asumida con la mayor densidad de matices. En primer término, se puede aducir que Ferrajoli incurre en el mismo defecto que imputa a Marshall. Porque, tras haber reprochado la confusión a que induce proponer una noción omnicomprensiva de la ciudadanía identificada con la titularidad de todos los derechos y libertades, avanza la propuesta de sustituir esa noción por la de personalidad, concebida también como el término de imputación de todos los derechos de la perso- 
na. A la postre, se trata de sustituir un término por otro, sin que se aprecien ventajas relevantes en tal opción.

Debe advertirse, al propio tiempo, que la expresión "derechos de la personalidad" no es menos excluyente, problemática y equívoca que la de "ciudadanía". Bastará recordar aquí, por ejemplo, que en un penetrante análisis crítico del Código de Napoleón, André-Jean Arnaud puso de relieve la discriminación existente en el respectivo status de "persona" entre los diversos sujetos de relaciones jurídico-privadas. Dicho ensayo pretendió ofrecer una panorámica totalizadora de la estructura del sistema jurídico privado francés concibiéndolo como un juego en el que intervienen unos jugadores (los distintos sujetos o personas jurídicas con su respectivo y desigual status que determina la exclusión de las «partidas» más importantes a algunos de ellos: las mujeres, los menores, los extranjeros, los indigentes sin domicilio fijo...) (Arnaud, 1973, 57 ss.).

La propuesta de Ferrajoli rompe, además, con la tendencia consolidada en el constitucionalismo y en la teoría de los derechos fundamentales, de establecer una nítida demarcación entre estos últimos y los derechos subjetivos privados. Los argumentos metodológicos y conceptuales avanzados por Jellinek al elaborar su doctrina de los derechos públicos subjetivos, han devenido clásicos para justificar la necesidad de no confundir estas categorías y mantienen intacta su validez (Jellinek, 1964, 19 ss.).

Idénticas reservas suscita la confusión entre derechos humanos y derechos fundamentales que se desprende del planteamiento de Ferrajoli. Importa no confundir estas dos categorías conceptualmente distintas, por más que exista una profunda interrelación entre ambas. Los derechos humanos poseen una insoslayable dimensión deontológica. Se trata de aquellas facultades inherentes a la persona que deben ser reconocidas por el derecho positivo. Cuando se produce ese reconocimiento aparecen los derechos fundamentales, cuyo nombre evoca su función fundamentadora del orden jurídico de los Estados de derecho. Por tanto, los derechos fundamentales constituyen un sector, sin duda el más importante, de los ordenamientos jurídicos positivos democráticos (Pérez Luño, 2003, 30 ss.).

Dista de ser diáfana la propuesta de Ferrajoli de concebir esos derechos de la "persona", en cuanto categoría alternativa de los derechos del "ciudadano", en el plano de la más estricta positividad. Su designio de no comprometer el concepto de derechos de la persona con postulados iusnaturalistas o filosofías de la justicia, le llevan a concebirlos como derechos establecidos, en cada tiempo y en cada época, por los ordenamientos jurídicos. Pero estas premisas parecen contravenir la dimensión universal que asigna Ferrajoli a esos derechos de la persona. Son, precisamente, los derechos humanos por su dimensión deontológica conexa con presupuestos iusnaturalistas de 
inequívoco signo cosmopolita, los que asumen esa dimensión de universalidad. Los derechos fundamentales, así como esa categoría imprecisa de los derechos de la persona, no participan del rasgo de la universalidad, porque se hallan delimitados por esas circunstancias "de lugar y de época" que contextualizan su reconocimiento positivo por los ordenamientos jurídicos (Pérez Luño, 2002a, 21 ss.).

La negación del concepto de ciudadanía no exime de plantear si es posible negarlo. Las dificultades teóricas no siempre pueden ser superadas por la exhuberancia del ímpetu. Negar la ciudadanía, porque su propia noción se ha hecho cuestionable y controvertida, puede resultar un mero acto o designio de la voluntad. El gran riesgo de determinadas actitudes doctrinarias, ha residido en el pasado y reside hoy, en que el intelectual decide, por sí y ante sí, elaborar unas definiciones convencionales de una institución y/o suprimir otras. Se trata de una arquitectura de conceptos, pero cuando la institución real y viva no coincide con ese modelo teórico, meramente "estipulativo", se la niega o se la considera abolida. Más discreto parece lo contrario, declarar superado o ficticio un concepto cuando no es congruente, porque no acierta a explicar la realidad.

Desde premisas analítico-lingüísticas, las definiciones estipulativas se conciben como el polo apuesto de las definiciones lexicales. Estas últimas, como se ha tenido ocasión de exponer anteriormente, consisten en la descripción de los usos de un término en el lenguaje; frente a ellas, las definiciones estipulativas entrañan propuestas o convenciones sobre el uso futuro de una expresión, al margen de su significado en la praxis lingüística. Las definiciones explicativas, por cuya modalidad se ha optado aquí para perfilar la noción de ciudadanía, pretenden superar los riesgos y limitaciones que aquejan a los dos otros tipos de definición. Respecto al mosaico de usos lingüísticos en los que las definiciones lexicales terminan por resolverse, la definición explicativa intenta ofrecer un itinerario de orientación sobre cómo debe ser utilizado un término, con el máximo rigor y claridad, en un determinado contexto cultural. En lo que atañe a las definiciones estipulativas, el modelo explicativo evita incurrir en la arbitrariedad que suele ser inherente a las estipulaciones definitorias, porque las definiciones explicativas se edifican sobre una selección de usos efectivos de un término.

Importa advertir, en todo caso, que no siempre las instituciones corresponden al perfil exacto de su definición explicativa; queda éste siempre como un elemento normativo, orientador o como una norma de perfeccionamiento. En cada Estado de derecho, se ha realizado de una forma distinta y con modalidades diversas el concepto de ciudadanía. Negar o tratar de abolir ese concepto, porque en la vida política del presente adolezca de insuficiencias o promueva disfunciones, no parece ser un método adecuado 
para resolver las cuestiones jurídicas y políticas que subyacen tras la idea de ciudadanía. Menos provechoso y más confuso todavía parece la sustitución semántica de este término por otros que, una vez formulados, tienen que hacer frente a las mismas aporías del que es sustituido. La vía más razonable parece, por todo ello, la de aceptar la noción de ciudadanía como un concepto jurídico-político que existe en los ordenamientos jurídicos del presente. La tarea abierta consiste, más bien, en comprobar si la disciplina jurídica de la ciudadanía se ha hecho cargo de las exigencias políticas del presente, para actualizar y rehabilitar el término, lo que es algo muy distinto de proclamar apresuradamente su abolición.

\section{La ciudadanía: vicisitudes de un concepto}

Existen conceptos e instituciones que, a lo largo de su decantación histórica, tienen suprema energía de perduración. Tal cualidad puede predicarse de la noción de ciudadanía, que a través de los tiempos ha expresado el vínculo jurídico que liga a las distintas formas de organización política con sus miembros. A partir de la modernidad, la ciudadanía significará el vínculo jurídico de pertenencia al Estado de derecho, y hará alusión al conjunto de derechos políticos en los que se desglosa la participación inmediata de sus titulares en la vida estatal.

Como todo status subjetivo, la ciudadanía se halla constituida por dos elementos: la titularidad y el contenido. La crisis que, en los últimos años, ha aquejado al concepto de ciudadanía incide en esos dos elementos. Así, el tránsito del Estado liberal al Estado social de derecho, planteó la ampliación del contenido de la ciudadanía para integrar en el seno de la "ciudadanía social" una serie de derechos, de índole económica, social y cultural que, en su significado estricto, rebasan la idea de ciudadanía. Por su parte, las teorías que apelan a la fragmentación de la ciudadanía representan intentos por redefinir sus formas de titularidad. La negación de la ciudadanía ha supuesto, a su vez, una tentativa de suplantar este término por otro, con la pretensión de que el nuevo se hiciera cargo de las nuevas exigencias de titularidad y contenido que gravitan sobre la ciudadanía.

Las perspectivas teóricas que han conducido a la crisis, incluso a la negación, de la ciudadanía han contribuido también a distorsionar y/o confundir los elementos constitutivos de su concepto. La tarea rehabilitadora de la definición de la ciudadanía, desde premisas explicativas, debe aportar la mayor dosis posible de claridad y rigor en la determinación del significado actual de los elementos constitutivos de la ciudadanía: contenido y titularidad. 


\subsection{Sobre el contenido de la ciudadanía: participación política y cultura civica}

"La ciudadanía social" indujo a confundir el concepto estricto de ciudadanía, circunscrito con los derechos de participación política, con una noción genérica y laxa en la que el contenido de dicho concepto coincide con la totalidad de derechos y libertades que corresponden a los miembros del Estado social de derecho. Esta confusión condujo a una pérdida de precisión significativa del concepto de ciudadanía. La denominada "ciudadanía social" debió entenderse como una nueva modalidad de ejercicio de los derechos políticos en el seno de un nuevo modelo de Estado de derecho, pero no como una ampliación de su objeto. El equívoco consistió en confundir el ámbito y modalidad de ejercicio del derecho con las facultades integradoras de su contenido. Pero, aun convicta de error, esta tesis ha tenido la virtualidad de hacernos caer en la cuenta de que la ciudadanía nunca ha sido inmune a los movimientos y fenómenos culturales, económicos, sociales y políticos que han contextualizado su ejercicio.

Las transformaciones o generaciones del Estado de derecho han supuesto contextos diferentes y diferenciados para el disfrute de la ciudadanía. Asimismo, fenómenos actuales como el multiculturalismo, los flujos migratorios, la globalización o el impacto de las nuevas tecnologías inciden directamente en las formas de ser ciudadano en las sociedades democráticas del presente. Pero, conviene reiterarlo, ese ámbito externo que contextualiza la actuación de la ciudadanía no es el contenido conformador de la misma.

Para elucidar el contenido de la ciudadanía en las sociedades liberales, estimo pertinente recordar las tesis de quien ha sido en las últimas décadas el más cualificado intérprete de la ciudadanía liberal: John Rawls. El prestigioso filósofo de Harvard, recientemente desaparecido, sostiene en su obra Political Liberalism, que debe ser "desechada la esperanza de una comunidad política unida en la afirmación de una única doctrina omnicomprensiva" $(1993,146)$. El pluralismo de visiones del mundo es para Rawls un elemento esencial de los Estados de derecho basados en el liberalismo político. La tolerancia y el pluralismo son, a la vez, exigencias teóricas y políticas, inspiradoras del orden interno, así como de las relaciones internacionales. El liberalismo político no puede identificarse con una visión comprensiva del mundo ni propugnarla. A diferencia del realismo moral que postula la posibilidad de intuir racionalmente los valores éticos fundamentales, el liberalismo político es una doctrina "constructivista". Según esa teoría, los valores ético-políticos son resultado de un proceso de construcción, que lleva a cabo la razón práctica a partir de una concepción compleja de la persona y de la sociedad que permite establecer la idea de lo que se considera razonable (1993,93 ss.). La aportación básica del constructivismo político- 
liberal reside en la posibilidad de arribar a un "consenso por superposición" (overlapping consensus), entre doctrinas comprensivas racionales que expresan visiones religiosas, filosóficas y morales diferentes. De este modo, las modernas sociedades democráticas pueden asegurar la coexistencia de una pluralidad de visiones del mundo contradictorias (1993,90 ss.y 144 ss.). El ejercicio de ese pluralismo político se expresa a través de ese consenso por superposición, que tiene unas reglas y vínculos que limitan su funcionamiento. El principal es la "carga o exigencia de razón" (burdens of reason ), es decir, la exigencia de que los desacuerdos o acuerdos se expresen a través de una argumentación racional y no estén provocados por el prejuicio, la desorientación o la ignorancia (1993, 67 ss.). Ello implica otorgar un papel central a la educación cívica como instrumento para el logro del consenso. De este modo, Rawls ha intentado rectificar el carácter irreal de su concepción de la "sociedad bien ordenada" defendida en su célebre obra anterior Teoría de la Justicia, en la que los principios de justicia eran establecidos a partir de una hipotética situación de "velo de la ignorancia" (es decir, sin contaminación de intereses particulares y concretos). En su obra sobre el $\mathrm{Li}$ beralismo Político, Rawls desea ofrecer una concepción moral practicable, estable y sensible a las circunstancias histórico-sociales que permita hacer viable la justicia en sociedades bien ordenadas empíricamente.

El consenso por superposición, o en la superposición, al que hacen referencia las tesis de Rawls, resulta útil para explicar el ejercicio de los derechos políticos que integran el contenido de la ciudadanía en las sociedades democráticas

En su libro The Law of Peoples (El derecho de gentes), Rawls considera la cultura política pública como el ámbito de racionalidad y tolerancia en el que los ciudadanos ejercen sus derechos de participación política en las democracias constitucionales (Rawls, 2001, 177ss.). En una época como la nuestra en la que las sociedades democráticas se debaten en una crisis de valores ético-políticos, que tiene uno de sus principales síntomas en lo que Vittorio Frosini ha calificado de "deseducación cívica" $(1986,79)$, resulta estimulante el esfuerzo de John Rawls por acentuar la importancia de la cultura cívica de la sociedad y "el ejercicio informado y consciente" de los derechos de ciudadanía.

En las sociedades liberales, es decir, aquellas que se hallan bien ordenadas en función de principios de justicia, los ciudadanos actúan como seres racionales, libres y dotados de autonomía moral, que intervienen en el debate político formando parte de distintas instituciones. La cultura política pública es el ámbito de expresión de las distintas doctrinas generales, sean de inspiración religiosa o secular. Tales doctrinas o concepciones políticas generales concurren en el debate político a través de lo que Rawls 
denomina "la estipulación". Con ello, quiere aludir a que esas doctrinas deben justificarse en términos razonables. No se exige " que sean correctas desde el punto de vista lógico, que estén abiertas al escrutinio racional o que estén sustentadas por pruebas"; basta con que actúen de acuerdo con la racionalidad práctica cifrada en argumentos razonables y persuasivos, tendentes a que esas opiniones sean ampliamente aceptadas. En todo caso, la estipulación en la que se expresa la cultura política pública, debe partir de los principios de la buena fe, la reciprocidad (respeto mutuo entre las distintas doctrinas generales que concurren al debate político) y la lealtad. Rawls considera que la lealtad de la ciudadanía democrática a los valores de las sociedades liberales se vertebra a través de la lealtad a sus respectivas doctrinas generales; la cultura política pública liberal es un cauce educativo para que la adhesión de los ciudadanos a los valores que informan la sociedad liberal no se conciba como un postulado abstracto, sino que se vertebre en el ejercicio libre de un debate político en el que la posibilidad de defender y propagar las ideas del grupo al que se pertenece, se vea enriquecido con el debate de otras doctrinas generales y todo ello promueva la adhesión a un sistema que permite ese ejercicio libre de la ciudadanía, "así, -en palabras de Rawls- la lealtad ciudadana al ideal democrático de la razón pública se fortalece por las razones correctas" (2001,178; cfr, sobre las implicaciones y aspectos críticos de estas tesis, Pérez Luño, 2003, 621 ss.).

Robert Dahl ha acertado a compendiar la importancia de la cultura cívica para el ejercicio de los derechos de participación política en los que se cifra el contenido de la ciudadanía en los Estados de derecho contemporáneos. "Una de las necesidades imperativas de los países democráticos -nos dice Dahl- consiste en potenciar las capacidades de los ciudadanos para que puedan implicarse íntegramente en la vida política" (Dahl, 1999, 211). El contenido de los derechos de participación política que dimana de la noción explicativa de la ciudadanía, rehabilitadora de su función en las sociedades liberales, se vertebra en un proyecto concreto e histórico de cultura política cívica. Tal noción nada tiene que ver con la imagen, forjada desde premisas multiculturalistas y comunitaristas, de una ciudadanía liberal, abstracta e indiferente a los apremios de tiempo y de lugar, cuyas salpicaduras todavía padece el debate conceptual de la ciudadanía en el presente.

\subsection{Sobre la titularidad de la ciudadanía: hacia una "ciudadanía multilateral"}

Las tesis desde las que se ha denunciado la fragmentación actual de la ciudadanía han contribuido a promover la necesidad actual de un replanteamiento de cuanto concierne a su titularidad. Desde la propia génesis del concepto moderno de ciudadanía, que coincide con la formación del 
Estado liberal, se ha venido produciendo una ampliación de sus formas de titularidad. No huelga recordar la exclusión de las mujeres, los menores, los analfabetos e indigentes de la titularidad cívica en las primeras versiones del Estado liberal, lo que representaba una negación de sí mismo. Los movimientos sociales y su inmediata incidencia en la decantación generacional del Estado de derecho han determinado la paulatina incorporación de esos grupos a la ciudadanía. Hoy el acceso a la titularidad de la ciudadanía se plantea, sobre todo, respecto a los extranjero e inmigrantes, siendo éste el gran reto abierto a la delimitación de su titularidad.

Una vez rota la ecuación entre ciudadano y nacional de un Estado, el concepto explicativo de la ciudadanía debe orientarse hacia una "ciudadanía multilateral", en el sentido anteriormente indicado (vid. supra n. 2.6). Se trata de avanzar una alternativa al modelo, hasta ahora vigente, de una "ciudadanía unilateral", entendida como vínculo político compacto y omnicomprensivo de todas la actividad participativa del individuo en el Estado. El fenómeno actual del desbordamiento político y jurídico del Estado en términos de "supraestatalidad" e "infraestatalidad", apoya ese desplazamiento de la ciudadanía hacia su versión multilateral. Así, por ejemplo, en el seno de la Unión Europea, pueden reconocerse y hacerse operativas hasta cuatro ciudadanías en sus Estados miembros con estructura federal o autonómica: la ciudadanía europea, la estatal, la federal o autonómica y la municipal.

La ciudadanía multilateral permitiría avanzar soluciones basadas en el pluralismo y la interculturalidad, tendentes a evitar el conflicto y la desintegración de los Estados multiculturales (Cortina, 1997; 2002; Lamo de Espinosa, 1995). Conviene no resbalar sobre el hecho de que en la Europa unida que se apresta a iniciar el curso del tercer milenio se plantee la reivindicación de derechos de determinadas minorías nacionales existentes en el seno de algunos de los Estados de la UE. En el marco de la Unión Europea, siguen existiendo colectivos étnicos que no se sienten parte de los Estados que conforman la Unión. Es notorio que existen bretones y corsos que no se sienten franceses; norirlandeses y escoceses que no se sienten británicos; catalanes y vascos que no se sienten españoles; lombardos y trentinos que no se sienten italianos; valones que nos se sienten belgas... pero, coetáneamente, otros miembros de esos mismos pueblos se sienten tales $\mathrm{y}$, al propio tiempo, ciudadanos plenamente integrados en los Estados de los que esas minorías étnicas forman parte. La solución ideal consistiría en la creación de unos espacios políticos en los que todos esos individuos pudieran ver plenamente satisfechas sus aspiraciones cívicas. Lo que ocurre es que tal pretensión parece evocar la cuadratura del círculo, ya que, la satisfacción plena y simultánea de las aspiraciones de unos aparece como incompatible con las de los otros. Sin embargo, existe un principio de esperanza: todos 
esos individuos, salvo casos extremos de un radicalismo étnico fundamentalista y violento, se sienten europeos. La ciudadanía europea puede ser el denominador común que permita, si no una solución definitiva de este grave conflicto, una vía tendente a conllevarlo.

Partir de la reformulación de la idea de ciudadanía me parece mas fértil que la de atender a las reivindicaciones nacionalistas radicales que esgrimen los derechos de los pueblos. Atender a tales reivindicaciones implicaría la creación de un mosaico de nuevos Estados en el seno de la Europa unida. Tal proyecto político parece desaconsejable en función de los siguientes argumentos:

$1^{\circ}$ ) Porque supondría una fragmentación política y, en consecuencia, una rémora para la consecución del ideal integrador que preside la construcción de una Europa unida. Implicaría, por tanto, una deslealtad e incongruencia respecto al valor-guía de la integración europea. Parece incoherente que los mismos pueblos que desean abandonar la pertenencia a Estados integrados en Europa, salgan por una puerta de ella y pretendan entrar, acto seguido, por otra a la misma Europa formada por los Estados a los que no deseaban pertenecer. Todo esto evoca la imagen de un vodevil, aunque sus consecuencias podrían ser mas trágicas que cómicas.

$2^{\circ}$ ) Porque, como se desprende del pensamiento kantiano, los cambios de fronteras constituyen siempre una amenaza si no para la paz perpetua, al menos para la paz estable.

$3^{\circ}$ ) Porque la experiencia de algunos de los Estados surgidos en Europa tras el desmoronamiento del bloque del Este, ha mostrado la falta de tolerancia de los partidos políticos nacionalistas, una vez instalados en el poder, hacia las minorías étnicas y culturales subsistentes en esos territorios (vid. supra, n. 4.2).

Por todo ello, parece más oportuno explorar la vía de una ciudadanía multilateral. La ciudadanía es el concepto jurídico que vincula, de forma estrecha e inmediata, al individuo con la comunidad política. Constituye el nexo básico de pertenencia y participación en una comunidad política. Durante mucho tiempo se consideró que tal vínculo era único y exclusivo entre el individuo y el Estado. Todavía en 1932, en sus célebres y, en tantos aspectos, clarividentes discursos ante las Cortes de la República, abogaba Ortega por amputar del Proyecto de Estatuto catalán la expresión "ciudadanía catalana". Pensaba Ortega que el mantenimiento de la misma daría a algunos individuos de España dos ciudadanías, que les haría en materia tan delicada "coleccionistas" (Ortega y Gasset, 1983, 11, 468).

A la altura de nuestro tiempo, parece conveniente admitir e incluso propugnar ese "coleccionismo" de ciudadanías, o sustituir la ciudadanía unilateral por una ciudadanía multilateral. El modelo de ciudadanía multilateral 
no sólo debería entenderse como la posibilidad de ser titular simultáneamente de varias ciudadanías, sino la posibilidad de ejercerlas con mayor o menor intensidad según los sentimientos de cada ciudadano hacia cada una de estas comunidades políticas. El éxito de tal iniciativa, como el de cualquier proyecto democrático, tiene como conditio sine qua non el fortalecimiento de la cultura política cívica. La formación y la madurez de los ciudadanos evitará que el ejercicio de la ciudadanía multilateral pueda degenerar en actitudes irreflexivas, arbitrarias o caprichosas.

La ciudadanía multilateral es un concepto que permite eludir los riesgos de privilegio y discriminación, aunque sea en su versión positiva, que evoca la idea de una ciudadanía diferenciada. Al propio tiempo, esta definición explicativa opera desde categorías jurídicas precisas y bien delimitadas, como lo son las propias nociones de ciudadanía municipal, autonómica o federal, y estatal o europea. No se trata, por tanto, de una propuesta conceptual de contornos nebulosos, imprecisos o difusos, sino de un método integrador para la articulación de modalidades de ciudadanía que ya se hallan consolidadas. Asimismo, la experiencia de los tratados de doble nacionalidad evidencia, que cuanto aquí se propone, no es una quimera ni una ensoñación utópica.

La cesión y, consiguientemente, erosión de la soberanía estatal que implica la pertenencia a la Europa unida (y que evidencia el sesgo anacrónico a las reivindicaciones soberanistas de determinados nacionalismos radicales), favorecerá la implantación de esa modalidad flexible y abierta que entraña la ciudadanía multilateral. También puede contribuir a su planteamiento y operatividad la progresiva apertura del sistema político europeo hacia formas de teledemocracia, que permitan conjugar la democracia representativa tradicional con experiencias de democracia directa participativa. La teledemocracia aparece hoy como un signo revitalizador del ejercicio de la ciudadanía acorde con las exigencias de la participación política en la era tecnológica, que contextualiza la titularidad, tutela y ejercicio de la ciudadanía en la hora presente.

Al declinar el año 2000, fue promulgada la Carta de los derechos fundamentales de la Unión Europea, cuyo Capítulo V se halla íntegramente dedicado a enunciar los derechos que dimanan de la ciudadanía europea. En la medida en que la integración de Europa consista en un movimiento ascensional, vertebrado sobre unos valores compartidos y un proyecto de desarrollo y convivencia común, será factible desnutrir y reabsorber las tentaciones nacionalistas hacia el particularismo y la fragmentación. No se trata de abolir las diferencias culturales que caracterizan a los distintos pueblos que habitan en los estados europeos, sino de ofrecerles un cauce de expresión que evite el conflicto y sea compatible con el proyecto integrador 
de Europa. Cabe aventurar que la ciudadanía multilateral podría contribuir a ello. En todo caso, el paradigma de la ciudadanía multilateral debería proponerse, como meta última y definitiva, recuperar el proyecto humanista cosmopolita de la modernidad, que continúa vigente: hacer posible una universalis civitatis en la que se consagre plenamente el auspiciado status mundialis hominis .

\section{Bibliografía}

Al-Farabí, A. N. (920): La ciudad ideal. Se cita por la traducción de Manuel Alonso Alonso. Presentación de Miguel Cruz Hernández. Madrid, Tecnos, 1985.

Arnaud, A.J. (1973): Essai d'analyse structurale du Code civil français. La règle du jeu dans la paix bourgeoise, LGDJ, París.

Boвbio, N.(1985 ): "La crisis de la democracia y la lección de los clásicos", en el vol. de N. Bobbio, G. Pontara y S. Veca, Crisis de la democracia, trad. cast. de J. Marfá, Ariel, Barcelona.

Basso, L. (1958): Il principe senza scettro, Feltrinelli, Milano.

Beltrán Pedreira, E. (2002): "Diversidad y deberes cívicos: liberalismo, ciudadanía y multiculturalismo", en el vol. col., a cargo de E. Díaz y J. L. Colomer, Estado justicia, derechos, Alianza, Madrid.

Cicerón, M.T. (51a.C.): De republica, se cita por la ed. cast. a cargo de A. D’Ors, Gredos, Madrid, 1991.

Contreras Peláez, F.J. (1994): Derechos sociales: teoría e ideología, Tecnos, Madrid.

Contreras Peláez, F.J., (1998): "Tres versiones del relativismo ético-cultural" en Persona y Derecho, n. 38.

Contreras Peláez, F.J., (2001): "Derechos colectivos, libertad individual y mitología comunitarista en Will Kymlicka" en el el vol., col. a cargo de F. J. Ansuátegui Roig, Una discusión sobre derechos colectivos, Dykinson \& Universidad Carlos III, Madrid.

Cortina, A. (1997): Ciudadanos del mundo, Alianza, Madrid.

CortinA, A. (2002): "Ciudadanía intercultural”, en el vol. col., a cargo de J. Conill, Glosario para una sociedad intercultural, Bancaja, Valencia.

DAHL, R. (1999): La democracia una guía para los ciudadanos, trad. cast. de F. Vallespín, Taurus, Madrid.

De Carreras i Serra, F. (1999): "Lenguas: Democracia y libertad", en el vol., a cargo de A. Santamaría, Foro Babel. El nacionalismo y las lenguas de Cataluña, Altera, Barcelona

De Castro Cid, B.,(1995): "La universalidad de los derechos humanos: ¿dogma o mito?", en Derechos y libertades, n.5.

De Lucas, J. (1992): Europa: ¿convivir con la diferencia? Racismo, nacionalismo y derechos de las minorías, Tecnos, Madrid.

De Lucas, J. (1994): El desafio de las fronteras. Derechos humanos y xenofobia frente a una sociedad plural, Temas de Hoy, Madrid. 
De LuCAS, J. (2002): "El vínculo social, entre ciudadanía y cosmopolitismo", en el vol col. El vínculo social, entre ciudadanía y cosmopolitismo, a cargo de Javier de Lucas, Tirant lo Blanch, Valencia.

Diderot, D. y D'Alembert, J. L.R. (1751/1765): Artículos políticos de la "Enciclopedia", ed. cast. a cargo de R. Soriano y A. Porras, Tecnos, Madrid, 1986.

Fariñas Dulce, Ma. J. (2000): Globalización, Ciudadanía y Derechos Humanos, Instituto de Derechos Humanos "Bartolomé de las Casas"Universidad Carlos III de Madrid \& Dykinson, Madrid.

Fernández García, E. (2001): Dignidad humana y Ciudadanía cosmopolita, Instituto de Derechos Humanos "Bartolomé de las Casas"Universidad Carlos III de Madrid \& Dykinson, Madrid.

Ferrajoli, L. (1999): Derechos y garantías. La ley del mas débil, Trotta, Madrid.

Ferrajoli, L. y otros, (2001): Los fundamentos de los derechos fundamentales, Trotta, Madrid.

Frosin. V. (1986): L'uomo artificiale. Etica e diritto nell'era planetaria, Spirali, Milano.

Fustel de Coulanges, D. (1996): La ciudad antigua, ed. cast. de C. García Gual, Edaf, Madrid.

Häberle, P. (1994): Europäische Rechtskultur, Nomos, Baden-Baden, 1994.

HäBerle, P. (1996): "Derecho Constitucional Común Europeo", trad. cast. de E. Mikunda, en el vol. col. ed. a cargo de A.E. Pérez Luño, Derechos humanos y Constitucionalismo ante el Tercer Milenio, Marcial Pons, Madrid.

Habermas, J. (1988): La modernidad: un proyecto inacabado, en su vol. Ensayos políticos, trad. cast. de R. García Cotarelo, Península, Barcelona.

Habermas, J. (1989): Identidad nacional y postnacional. trad., cast., de M. Jiménez Redondo, Tecnos, Madrid.

Habermas, J. (1997): Más allá del Estado nacional, trad., cast., de M. Jiménez Redondo, Trotta, Madrid.

Heller, H. (1978): "Rechtsstaat oder Diktatur?", en la op. col. a cargo de M. Tohipidur, Der bürgerliche Rechtsstaat, Suhrkamp, Frankfurt a.M.

JelLineK, G. (1964): System der subjektiven öffentlichen Rechte, reimp. de la ed. de 1919, Scientia, Aalen.

Kant. I. (1793): "Ueber den Gerneinspruch: Das mag in der Theorie richüg sein, taugt aber nichtfür die Praxis", en Kants gesammelte Schriften, vol. VIII, Walter de Gruyter, Berlín, 1968 (existe trad. cast. de J. M. Palacios, M.F. Pérez y R. Rodríguez Aramayo, Tecnos, Madrid, 1986).

Kymlicka, W. (1989): Liberalism, Community and Culture, oxford University Press, Oxford.

Kymlicka, W.(1996): Ciudadanía multicultural, Paidós, Barcelona.

Kymlicka, W. (2003): Nacionalismo, multiculturalismo y ciudadanía, trad., cast., de T. Fernández Aúz, Paidós, Barcelona.

Lamo de Espinosa, E. (1995): Culturas, Estados, Ciudadanos, Alianza, Madrid.

Laporta, F. (2001): "Inmigración y respeto" en Claves de Razón Práctica, no 114.

Llano Alonso, F. (2002): El humanismo cosmopolita de I. Kant, con Prólogo de A. E. Pérez Luño, Universidad Carlos III \& Dykinson, Madrid. 
Kymlicka, W.(1996): Ciudadanía multicultural, Paidós, Barcelona.

MARX , K. (1843): “Zur Judenfrage”, en Marx-EngeIs Werke, Dietz, Berlín, 1977, vol.1. (Existe trad. cast. en K. Marx, Escritos de juventud, ed. a cargo de W. Roces, Fondo de Cultura Económica, México, 1982). Peces-Barba, G. (1978): Libertad, poder y socialismo, Civitas, Madrid.

Nussbaum, M. (1999): Los límites del patriotismo. Identidad, pertenencia y "ciudadanía mundial", Paidós, Barcelona.

Ortega y Gasset, J. (1931): "Rectificación de la República" se cita por Obras Completas, Alianza Editorial \& Revista de Occidente, Madrid, vol. 11, 1983.

Ortega y Gasset, J. (1932): "El estatuto catalán” se cita por Obras Completas, Alianza Editorial \& Revista de Occidente, Madrid, vol. 11, 1983.

Peces-Barba, G. (1982): Tránsito a la Modernidad y derechos fundamentales, Mezquita, Madrid.

Pérez LuÑo, A. E. (1981): "El concepto de igualdad como fundamento de los derechos económicos, sociales y culturales”, en Anuario de Derechos Humanos, tomo 1.

Pérez Luño, A. E. (1985): "Dimensiones de la igualdad material”, en Anuario de Derechos Humanos, tomo 3.

Pérez Luño, A.E. (1993): El desbordamiento de las fuentes del Derecho, Real Academia Sevillana de Legislación y Jurisprudencia, Sevilla.

Pérez Luño, A.E. (2001a): "El papel de Kant en la formación histórica de los derechos humanos", en el vol. col., a cargo de G. Peces-Barba y E. Fernández, Historia de los derechos fundamentales. T. II, Siglo XVIII, vol. II, La Filosofía de los derechos humanos, Dykinson, \& Instituto de Derechos Humanos Bartolomé de las Casas de la Universidad Carlos III de Madrid.

Pérez LuÑo, A.E. (2001b): "Diez tesis sobre la titularidad de los derechos humanos", en el vol., col. a cargo de F. J. Ansuátegui Roig, Una discusión sobre derechos colectivos, Dykinson \& Universidad Carlos III. Madrid

Pérez LuÑo, A.E. (2002a): La universalidad de los derechos y el Estado constitucional, con Prólogo de L. Villar Borda, Universidad Externado de Colombia, Bogotá.

Pérez LuÑo, A.E. (2002b): Teoría del derecho. Una concepción de la experiencia jurídica, en col. con A. Cabrera, R. González-Tablas, Ruiz del la Cuesta, Tecnos, Madrid, $2^{\mathrm{a}}$ ed.

Pérez Luño, A.E. (2002c): Lecciones de Filosofía del Derecho. Presupuestos para una filosofía de la experiencia jurídica, $8^{\mathrm{a}}$ ed., $3^{\mathrm{a}}$ ed. en Mergablum, Sevilla.

Pérez LuÑo, A.E. (2003): Derechos humanos, Estado de Derecho y Constitución, Tecnos, Madrid; $8^{\mathrm{a}}$ ed

Pérez Luño, A. E. y Contreras Peláez, F. (2001): "Kant y los derechos humanos", Historia de los derechos fundamentales. T. II, Siglo XVIII,vol.II, La Filosofía de los derechos humanos, Dykinson, \& Instituto de Derechos Humanos Bartolomé de las Casas de la Universidad Carlos III de Madrid.

Prieto Sanchís, L. (1990): Estudios sobre derechos fundamentales, Debate, Madrid.

Rawls, J. (1993): Political Liberalism, Columbia University Press, New York,, p. 146 (existe trad., cast., de A. Domech, Crítica, Barcelona, 1996). 
RAWLs, J. (2001): El derecho de gentes y "una revisión de la idea de razón pública", trad. cast. de H. Valencia, Paidós, Barcelona.

Rivero Ysern, J. L. (1993): Manual de Derecho local, Civitas, Madrid, $2^{\text {a }}$ ed.

Sartori, G. (2001): La sociedad multiétnica. Pluralismo, multiculturalismo y extranjeros, Taurus, Madrid.

Smend, R. (1985): “Ciudadano y burgués en el Derecho político alemán”, en su vol. Constitución y Derecho Constitucional, trad. cast. de J. M. Beneyto, Centro de Estudios Consitucionales, Madrid.

Toynbee, A. J. (1970): Estudio de la Historia, trad. cast. de L.A. Bixio, Alianza, Madrid, vol.I.

VeCA, S. (1990): Cittadinanza, Feltrinelli, Milano.

VI GIL, E. (1990): "Las paradojas de la democracia" en Anuario de Filosofía del Derecho, vol. 7.

Walzer M. (2001) "El concepto de "ciudadanía" en una sociedad que cambia", en su vol. Guerra, política y moral, ed. cast. de R. Grasa, Paidós, Baracelona. 
$\triangle \quad$ DOXA 25 (2002) 